\title{
Correction to: Exploration of a cultural-adaptation of the EQ-5D for Thai population: A "bolt-on" experiment
}

\author{
Krittaphas Kangwanrattanakul ${ }^{1,2} \cdot$ Cynthia R. Gross $^{3} \cdot$ Montaya Sunantiwat $^{1} \cdot$ Montarat Thavorncharoensap $^{1}$ (i)
}

Published online: 18 October 2021

(c) Springer Nature Switzerland AG 2021

\section{Correction to: \\ Quality of Life Research (2019) 28:1207-1215 \\ https://doi.org/10.1007/s11136-018-2072-4}

In the original publication of the article, a footnote was not included under Fig. 1 with the copyright and trademark line of EQ-5D and required references for the publication of EQ-5D. The corrected Fig. 1 with the footnote is given below.

The original article can be found online at https://doi.org/10.1007/ s11136-018-2072-4.

Montarat Thavorncharoensap

montarat.tha@mahidol.ac.th

1 Division of Social and Administrative Pharmacy,

Department of Pharmacy, Faculty of Pharmacy,

Mahidol University, 447 Sri-Ayuthaya Rd., Rajathevi,

Bangkok 10400, Thailand

2 Faculty of Pharmaceutical Sciences, Burapha University,

169 Long-Hard Bangsean Rd., Sansuk Sub-district, Mueang

District, Chonburi 20131, Thailand

3 Department of Experimental and Clinical Pharmacology, College of Pharmacy, University of Minnesota, Minneapolis, USA 
Activities related to bending knees (e.g. Performing activities through meditation position, squatting, kneeling, sitting with folded legs to one side, crawling, etc.)

I have no problems with performing activities related to bending knees

I have slight problems with performing activities related to bending knees

I have moderate problems with performing activities related to bending knees

I have severe problems with performing activities related to bending knees

I am unable to perform activities related to bending knees

Interpersonal relationships (e.g. family members, siblings and relatives, friends, colleagues, neighbors, etc.)

I have no problems with interpersonal relationships

I have slight problems with interpersonal relationships

I have moderate problems with interpersonal relationships

I have severe problems with interpersonal relationships

I have extreme problems with interpersonal relationships

(C) EuroQol Research Foundation. EQ-5D ${ }^{\mathrm{TM}}$ is a trade mark of the EuroQol Research Foundation. This is a modified EQ-5D. Reproduction and/or use of this modified EQ-5D without the prior consent of EuroQol is not allowed. For permission, please register via the online EuroQol user registration form: www.euroqol.org.

Fig. 1 Thai-specific dimensions description

Publisher's Note Springer Nature remains neutral with regard to jurisdictional claims in published maps and institutional affiliations. 